\title{
CICLAGEM DE NUTRIENTES DE UM PLANTIO DE EUCALIPTO EM REGENERAÇÃO DE ESPÉCIES NATIVAS NO SUB-BOSQUE
}

\author{
Daniel Costa de Carvalho ${ }^{1}$, Marcos Gervasio Pereira ${ }^{1 *}$, Luciano Oliveira Toledo ${ }^{2}$, Cátia Aparecida Simon ${ }^{3}$, \\ Johnny da Silva Rodrigues ${ }^{2}$, Júlio César Feitosa Fernandes ${ }^{1}$, Eduardo Carvalho Silva Neto ${ }^{1}$
}

\author{
${ }^{1}$ Universidade Federal Rural do Rio de Janeiro, Departamento de Solos, Seropédica, Rio de Janeiro, Brasil - \\ danielcostadecarvalho@gmail.com; mgervasiopereira01@gmail.com; julionrtfeitosa@yahoo.com.br; netocseduardo@yahoo.com.br \\ ${ }^{2}$ Instituto Federal de Educação, Ciência e Tecnologia do Espírito Santo, Vitória, Espirito Santo, Brasil - luciano.toledo@mec.gov.br; \\ johnnyrodriguesnl@hotmail.com \\ ${ }^{3}$ Universidade Federal de Mato Grosso do Sul, Campus de Chapadão do Sul, Chapadão do Sul, Mato Grosso do Sul, Brasil - \\ catiasimonsimon@gmail.com
}

Recebido para publicação: 24/10/2015 - Aceito para publicação: 26/11/2016

\begin{abstract}
Resumo
O processo de ciclagem de nutrientes é importante para a sustentabilidade das formações florestais naturais e implantadas. Buscando contribuir com um melhor entendimento sobre esse processo, o objetivo deste estudo foi avaliar a ciclagem de nutrientes em um plantio puro de eucalipto com regeneração de espécies nativas em seu sub-bosque. Para o aporte e decomposição da serapilheira foram utilizados, respectivamente, coletores cônicos e litter bags. Posteriormente foram separadas as frações foliares de eucalipto (Corymbia citriodora) (EUC), regeneração nativa do sub-bosque (REG) e da fração controle com espécies de uma Floresta Estacional Semidecidual (FES). A seqüência do retorno de macronutrientes pelas folhas seguiu a mesma ordem para todas as frações foliares: $\mathrm{N}>\mathrm{K}>\mathrm{P}$. As folhas de FES aportaram mais macronutrientes ao solo, enquanto EUC e REG aportaram a mesma quantidade. A degradação foliar foi mais elevada para FES, seguida da REG e do EUC. A velocidade de liberação de macronutrientes das folhas do EUC obedeceu a seguinte ordem: $K>P>N$. Enquanto para a FES e REG, o retorno foi na sequência: $N>K>P$ e $K>P>N$, respectivamente. Esses resultados demonstram a importância da conservação da serapilheira nos ambientes estudados, principalmente na proteção e retorno de nutrientes para esses solos.

Palavras-chave: Plantios homogêneos; material orgânica; serapilheira; aporte e decomposição de biomassa; conservação do solo.
\end{abstract}

\begin{abstract}
Nutrient cycling in the eucalyptus plantation with a regeneration of native species in understory. The nutrient cycling process is important for the sustainability of natural and planted forest formations. Therefore, the aim of this study was to evaluate the contribution of Nutrient cycling in the eucalyptus plantation with a regeneration of native species in understory. For deposition and decomposition of litter were used conical collectors and litter bags respectively. Subsequently were separated the foliar fractions of eucalyptus (Corymbia citriodora) (EUC), the native understory regeneration (REG) and a control with fraction of Semideciduous Forest species (FES). The sequence of the return of nutrients through the leaves followed the same order for all foliar fractions: $N>K>P$. The leaves of FES deposited more macronutrients on the ground, while EUC and REG contributed the same amount. The leaf degradation was higher for FES, then the REG and EUC. The rate of nutrients release from the EUC leaves followed the order $\mathrm{K}>\mathrm{P}>\mathrm{N}$, while FES and REG this return following order $\mathrm{N}>\mathrm{K}>\mathrm{P}$ and $\mathrm{K}>\mathrm{P}>\mathrm{N}$ respectively. These results demonstrate the importance of litter conservation in the study site, especially in the protection and nutrient return of these soils.

Keywords: Homogeneous plantations; organic material; litter input and decomposition of biomass; soil conservation.
\end{abstract}

\section{INTRODUÇÃO}

O aporte e a transformação da serapilheira são fundamentais para manutenção das propriedades dos solos tanto para florestas nativas quanto para os plantios de espécies exóticas comerciais (PINTO et al., 2008; SCHUMACHER et al., 2013). A deposição da serapilheira é contínua ao longo do ano, sendo sua produção e decomposição influenciadas por fatores geográficos, climáticos, edáficos, fisiológicos, antrópicos e também devido à tipologia florestal. Esses fatores e processos de ciclagem da serapilheira são ainda mais importantes quando estão relacionados aos solos de baixa fertilidade natural (GAMA- BALIEIRO et al. 2004; BARLOW et al., 2007).

A serapilheira é constituída por materiais vegetais depositados na superfície do solo, como folhas, cascas, ramos e material reprodutivo, além de fragmentos animais. Um dos principais componentes da serapilheira são as folhas, podendo contribuir com mais de $70 \%$ do material adicionado. Estes componentes atuam na superfície do solo como um sistema de entrada e saída, via aporte de material orgânico e sua decomposição. Estes processos são importantes na restauração da fertilidade do solo, principalmente em áreas em início de sucessão ecológica e na manutenção da produção sustentável em

FLORESTA, Curitiba, PR, v. 47, n. 1, p. 17 - 27, jan. / mar. 2017.

Carvalho, D. C. de et al.

ISSN eletrônico 1982-4688

DOI: $10.5380 /$ rf.v47i1.43652 
plantios comerciais, como no cultivo das espécies de eucaliptos (GAMA-RODRIGUES; BARROS, 2002; CUNHA et al., 2005; BARLOW et al., 2007).

O eucalipto tem sido uma das principais essências florestais utilizadas em programas de reflorestamento (ABRAF, 2013; BARRETO et al., 2014). Essa espécie apresenta alta eficiência no uso de nutrientes, produzindo como consequência, serapilheira de baixa qualidade nutricional, quando comparada à serapilheira produzida pelas florestas tropicais naturais (GAMA-RODRIGUES; BARROS, 2002). Muitos plantios de eucalipto são manejados de forma inadequada ou até mesmo abandonados, levando à degradação do solo, alterando assim o ciclo dos nutrientes. Esses processos, podem levar, ao longo do tempo, à colonização do sub-bosque desses povoamentos por espécies nativas, sejam elas arbóreas e/ou arbustivas (SOUZA et al., 2007). Entretanto, além do aumento da biodiversidade local, ainda não se sabe qual a contribuição da ciclagem de nutrientes dessa regeneração de espécies nativas no sub-bosque de plantios de eucalipto.

Sendo assim, este estudo fundamenta-se na hipótese que a serapilheira oriunda de diferentes coberturas vegetais, nativas e plantadas, apresentam taxas de deposição e retorno de nutrientes foliares diferenciadas. Para verificar a hipótese descrita acima, o objetivo deste estudo foi avaliar a ciclagem de nutrientes de uma monocultura de eucalipto com regeneração de espécies nativas em seu sub-bosque.

\section{MATERIAL E MÉTODOS}

O estudo foi realizado no Instituto Federal de Educação, Ciência e Tecnologia do Espírito Santo (IFET-ST) no município de Santa Teresa. O IFET-ST está localizado na porção noroeste do município, em uma região denominada Vale do Canaã, com altitude média de aproximadamente 100 metros (Figura 1). O clima da região é enquadrado como temperado úmido, com inverno seco e verão quente (Cwa) segundo a classificação climática proposta por Köppen.

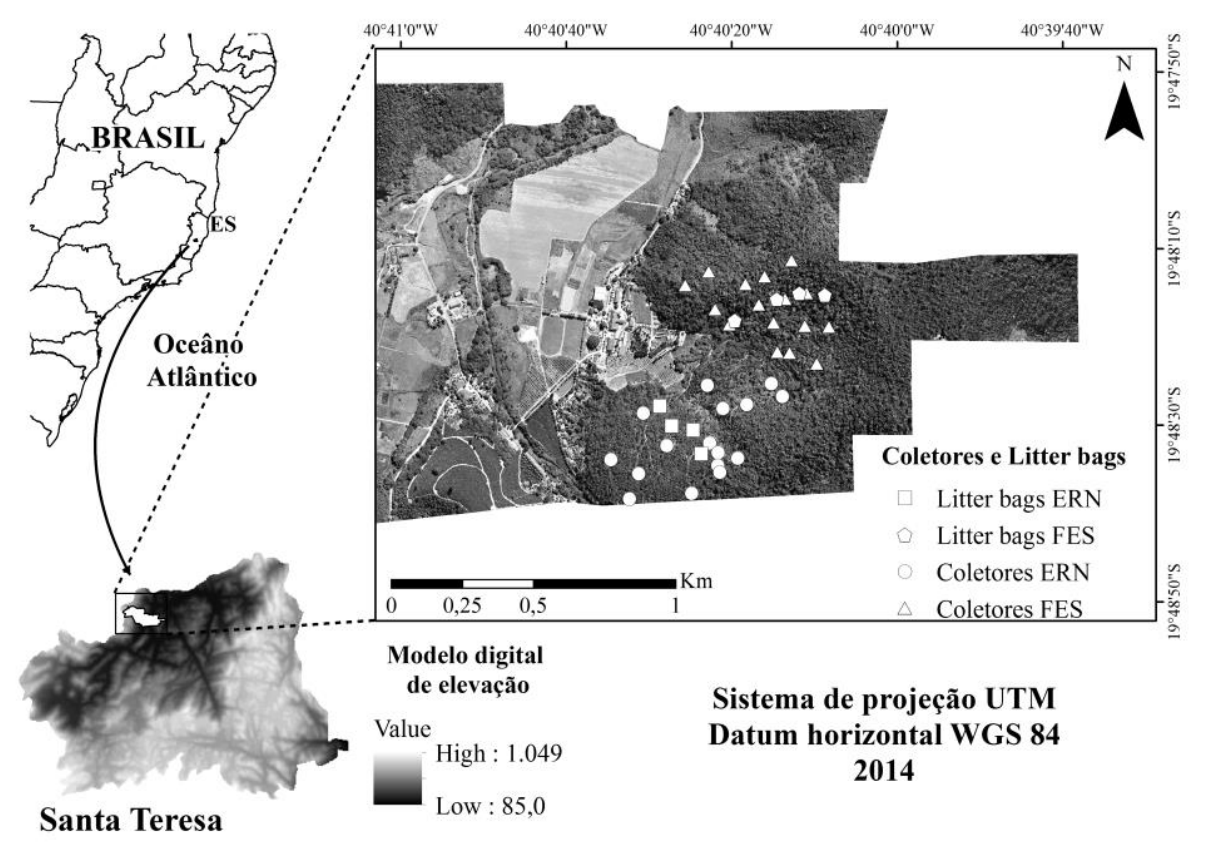

Figura 1. Disposição dos coletores e litter bags na área de estudo localizada em Santa Teresa, ES. Legenda: ERN Plantio de eucalipto com regeneração de espécies nativas; FES - Floresta Estacional Semidecidual.

Figure 1. Location of collectors and litter bags, Santa Teresa, ES. Legend: eucalyptus plantation with regeneration of native species (ERN) and Semideciduous Forest (FES).

Para realização do estudo duas áreas foram selecionadas no IFES-ST. A primeira trata-se de um povoamento de eucalipto com 55 ha e formado pela espécie Corymbia citriodora (Hook.) K. D. Hill \& L. A. S. Johnson (ERN). Esta área possui ainda seu sub-bosque colonizado por uma regeneração de espécies nativas (REG). A segunda área, utilizada neste estudo como controle e como parâmetro de comparação do estádio original da paisagem local, possui aproximadamente 86 ha e foi classificada como Floresta Estacional Semidecidual Submontana (FES) (INSTITUTO BRASILEIRO DE GEOGRAFIA E ESTATÍSTICA (IBGE), 2012).

De acordo com dados da instituição, até o ano de 1975 a área denominada ERN era semelhante ao fragmento florestal FES. Neste mesmo ano, a floresta foi convertida - sem nenhum trato cultural - em uma pastagem (Brachiaria sp.) e mantida por aproximadamente 5 anos. Em 1980, a mesma área antes ocupada por uma pastagem, foi submetida a uma nova cultura, sendo então ocupada por uma monocultura de $C$. citriodora até os dias atuais. Devido à falta de 
manejo adequado, por aproximadamente 15 anos, este povoamento possui atualmente indivíduos arbóreos de $C$. citriodora com cerca de $20 \mathrm{~m}$ de altura e uma regeneração de espécies nativas, composta por indivíduos arbóreos e arbustivos em seu sub-bosque (REG). A composição das espécies desse sub-bosque (REG) reflete $41 \%$ de similaridade florística com o fragmento de FES vizinho (dados não publicados) (Tabela 1).

Tabela 1. Caracterização da vegetação do povoamento de Corymbia citriodora (ERN), da regeneração de espécies nativas (REG) presente no sub-bosque do plantio de eucalipto e da Floresta Estacional Semidecidual (FES) no município de Santa Teresa, Espírito Santo.

Table 1. Characteristics of Corymbia citriodora stand with regeneration of native species (ERN), regeneration of native species (REG) and Semideciduous forest (FES) in Santa Teresa, Espírito Santo State.

\begin{tabular}{|c|c|c|c|}
\hline \multirow{2}{*}{ Parâmetros amostrais e estruturais } & \multicolumn{2}{|c|}{ ERN } & \multirow{2}{*}{ FES } \\
\hline & C. citriodora & REG & \\
\hline Tamanho da área amostrada (ha) & 1,1 & & 0,8 \\
\hline Número de parcelas amostradas (10 m x $5 \mathrm{~m})$ & 220 & & 160 \\
\hline Número de indivíduos vivos amostrados & 396 & 600 & 1.063 \\
\hline Densidade (ind ha ${ }^{-1}$ ) & 427 & 515 & 1.330 \\
\hline Área basal média $\left(\mathrm{m}^{2} \mathrm{ha}^{-1}\right)$ & 7,52 & 8,04 & 23,16 \\
\hline Altura média (m) & 17,3 & 8,7 & 15,3 \\
\hline Número de famílias & & 21 & 30 \\
\hline Número de espécies & & 61 & 97 \\
\hline Número de espécies de Fabaceae & & 21 & 23 \\
\hline Estádio sucessional $^{1}$ & & Inicial & Avançada \\
\hline Índice de diversidade de Shannon (nat.ind ${ }^{-1}$ ) & & 3,23 & $3,81^{3}$ \\
\hline Similaridade florística ${ }^{2}$ & & & \\
\hline
\end{tabular}

Legenda: ${ }^{1}$ Resolução CONAMA n ${ }^{\circ} 29$, de 7 de dezembro de $1994 ;{ }^{2}$ Coeficiente de Sorensen

Para a avaliação do aporte de serapilheira foram instalados 16 coletores cônicos em cada área de estudo. Esses coletores foram distribuídos em curva de nível em uma topossequência (Figura 1). Esse procedimento foi realizado para abranger melhor as áreas avaliadas. Os coletores foram confeccionados a partir de uma tela de náilon (4 mm) com uma área de $0,3316 \mathrm{~m}^{2}$ de abertura, e foram fixados a aproximadamente 0,5 metros acima da superfície do solo. O aporte de serapilheira em cada uma das áreas (ERN e FES) foi avaliado mensalmente, durante o período de agosto de 2010 a julho de 2011.

Após a coleta, a serapilheira foi identificada e classificada entre as seguintes frações: folhas, ramos, materiais reprodutivos e outros materiais não identificados. Os coletores da área ERN continham a serapilheira de duas fontes: uma do eucalipto (EUC) e outra da regeneração de espécies nativas (REG).

Para comparação do aporte de biomassa, retorno de nutrientes e a influência da sazonalidade entre as diferentes fontes de serapilheira (EUC, REG e FES), foi utilizada somente a fração foliar de cada uma dessas fontes. Esse procedimento foi realizado tendo em vista que nos coletores da área de ERN não era possível diferenciar quais frações (galhos, sementes e outros materiais) pertenciam a fonte EUC e quais pertenciam a fonte REG. Aliado a isso, é importante considerar que a maior proporção de aporte de biomassa e nutrientes vem do material foliar contido na serapilheira.

A quantidade de serapilheira e nutrientes produzidos em cada área de estudo, foi estimada pela expressão descrita a seguir, elaborada por Lopes et al. (2002): Produção de serapilheira $\left(\mathrm{Mg} \mathrm{ha}^{-1}\right.$ ano $\left.^{-1}\right)=(\Sigma$ produção mensal de serapilheira $\left.\left(\mathrm{Mg} \mathrm{mês}^{-1}\right) \times 10.000\right) /$ Área do coleto $\left(\mathrm{m}^{2}\right)$. Em cada coleta, uma parte da fração foliar da serrapilheira foi separada e moída. A partir dessa fração foram quantificados os teores de nitrogênio, fósforo e potássio segundo Tedesco et al. (1995). O conteúdo de nutrientes das folhas foi determinado pela relação entre o teor e a massa aportada durante o ano de estudo.

$\mathrm{Na}$ correlação do material foliar com variáveis climáticas foi utilizada uma série histórica de 20 anos (1988 a 2008), disponibilizados pela estação meteorológica automática do IFET-ST. As variáveis climáticas utilizadas foram elaboradas com base nos valores mensais de temperatura do ar, temperatura máxima, temperatura mínima, evapotranspiração, precipitação e umidade relativa.

Para a avaliação da decomposição foram utilizadas amostras de material foliar depositado nos coletores cônicos. Na área de ERN foram triadas as folhas de EUC e da REG, excluindo as outras frações da serapilheira como galhos e sementes. Para efeito de comparação e controle este procedimento foi repetido na área de Floresta Estacional Semidecidual (FES), obtendo-se folhas da mesma.

Após triagem, as folhas foram secas em estufa de circulação forçada de ar a $65^{\circ} \mathrm{C}$, até que fosse atingido peso constante. Após a secagem, $10 \mathrm{~g}$ desse material foram acondicionadas em sacolas de polivinil "litter bags", segundo (ANDERSON; INGRAM, 1993). Os "litter bags" utilizados foram feitos a partir de uma tela de náilon (4 mm), com medidas de $25 \times 25 \mathrm{~cm}\left(625,00 \mathrm{~cm}^{2}\right)$ e aproximadamente $1,5 \mathrm{~cm}$ de altura. Foram utilizados 20 "litter bags" contendo material foliar oriundo das diferentes fontes de serrapilheira (EUC, REG e FES). Os "litter bags" contendo folhas de EUC e da REG foram instalados na área do plantio de eucalipto, enquanto os litter bags com folhas de FES foram

FLORESTA, Curitiba, PR, v. 47, n. 1, p. 17 - 27, jan. / mar. 2017.

Carvalho, D. C. de et al.

ISSN eletrônico 1982-4688

DOI: $10.5380 /$ rf.v47i1.43652 
instalados na Floresta Estacional Semidecidual. Todos os litter bags foram instalados em uma topossequência (Figura 1) e no início do período de estiagem da região (20 de maio de 2011).

As coletas foram realizadas em intervalos de 30,60, 90 e 120 dias, contados a partir do início da instalação. Em cada coleta foram retirados cinco litter bags por tratamento (EUC, REG e FES), totalizando cinco repetições. Após a coleta as amostras foram secas em estufa de circulação forçada de ar a $65^{\circ} \mathrm{C}$, até que fosse atingido peso constante e posteriormente pesadas.

A quantificação das taxas de decomposição da biomassa foliar e dos macronutrientes foliares (N, P e K) foram obtidas através de medidas de perda de massa, calculando-se a diferença entre a quantidade inicial do material original contido em cada litter bag (10 g) e a quantidade que permaneceu no período de cada coleta. Com estes valores, ao longo do período estudado, foi estimada a constante de decomposição (k), conforme Thomas e Asakawa (1993), pelo modelo de decaimento exponencial. O tempo de meia-vida $\left(\mathrm{t}^{1 / 2}\right)$ do material foi estimado conforme Rezende et al. (1999). As curvas que caracterizam a decomposição e liberação dos nutrientes do material foliar foram confeccionadas por meio de regressão e expressas em porcentagem. Em cada coleta, uma parte da fração foliar da serrapilheira foi separada e moída, e nela foram quantificados os teores de nitrogênio, fósforo e potássio segundo Tedesco et al. (1995). O conteúdo destes nutrientes foi obtido a partir da multiplicação dos teores pela massa de material.

Os dados de aporte de serapilheira foram submetidos à análise de normalidade da distribuição dos erros (teste de Lilliefors) e homogeneidade das variâncias dos erros (teste de Cochran). Os dados que atenderam às pressuposições (valores médios) foram comparados por meio do teste de Tukey. Para determinar a correlação entre produção da fração foliar e as variáveis climáticas com as diferentes fontes de serapilheira (EUC, REG e FES) foi utilizado o método de Pearson.

\section{RESULTADOS E DISCUSSÃO}

\section{Produção de serapilheira nas duas áreas de estudo}

Os valores médios de deposição total anual entre as áreas de estudo não diferiram estatisticamente pelo teste de Tukey $(\mathrm{p}<0,05)$ (Tabela 2). Mesmo com a contribuição da regeneração nativa na área de ERN, o aporte total de serapilheira se mostrou semelhante ao da FES.

Tabela 2. Produção média* mensal de serapilheira nas áreas de eucalipto com regeneração nativa (ERN) e na Floresta Estacional Semidecidual (FES) no município de Santa Teresa, Espírito Santo.

Table 2. Average monthly* litter production of the eucalyptus with native regeneration (ERN) and Semideciduous Forest (FES) in Santa Teresa, Espírito Santo State.

\begin{tabular}{|c|c|c|c|c|}
\hline \multirow{3}{*}{ Mês } & \multicolumn{4}{|c|}{ Áreas de estudo } \\
\hline & \multicolumn{2}{|c|}{ ERN } & \multirow{2}{*}{\multicolumn{2}{|c|}{ FES }} \\
\hline & \multicolumn{2}{|c|}{ - } & & \\
\hline Agosto & $0,32(0,072)$ & $\mathrm{c} B$ & $1,01(0,102)$ & a A \\
\hline Setembro & $0,24(0,054)$ & $\mathrm{b} \mathrm{BC}$ & $0,57(0,090)$ & a B \\
\hline Outubro & $0,16(0,035)$ & a $\mathrm{C}$ & $0,24(0,043)$ & a D \\
\hline Novembro & $0,25(0,029)$ & a BC & $0,32(0,045)$ & a $C D$ \\
\hline Dezembro & $0,85(0,115)$ & a A & $0,47(0,073)$ & $\mathrm{b} B C$ \\
\hline Janeiro & $0,88(0,123)$ & a A & $0,34(0,073)$ & b CD \\
\hline Fevereiro & $0,84(0,123)$ & a A & $0,39(0,086)$ & $\mathrm{b} \mathrm{BC}$ \\
\hline Março & $0,56(0,070)$ & a $\mathrm{AB}$ & $0,36(0,041)$ & a $\mathrm{CD}$ \\
\hline Abril & $0,15(0,019)$ & a $\mathrm{C}$ & $0,19(0,019)$ & a D \\
\hline Maio & $0,23(0,037)$ & a BC & $0,25(0,046)$ & a D \\
\hline Junho & $0,30(0,059)$ & a BC & $0,44(0,081)$ & a BC \\
\hline Julho & $0,58(0,139)$ & a $\mathrm{AB}$ & $0,78(0,121)$ & a $\mathrm{AB}$ \\
\hline Total anual & 5,36 & & 5,34 & \\
\hline Média & $0,45(0,08) \mathrm{a}$ & & $0,45(0,07) \mathrm{a}$ & \\
\hline CV\% & 63,14 & & 53,6 & \\
\hline
\end{tabular}

O aporte total anual de serapilheira em FES vai de encontro com valores observados por outros autores em áreas naturais de Florestas Estacionais Semideciduais, variando de 4,5 a 13,6 $\mathrm{Mg} \mathrm{ha}^{-1}$ (SOUZA; DAVIDE, 2001; VITAL et al., 2004; PINTO et al., 2008; PINTO et al., 2009). Para a área de ERN o aporte total anual de serapilheira foi inferior ao observado por outros autores que descrevem valores de aporte de serapilheira entre 5,36 e $11,84 \mathrm{Mg} \mathrm{ha}^{-1}$ em plantios de eucalipto formados por diferentes espécies (SOUZA; DAVIDE, 2001; GAMA-RODRIGUES; BARROS, 2002; BALIEIRO et al. 2004; CUNHA et al. 2005; SCHUMACHER et al. 2013). As diferenças do aporte de serapilheira observada em outros estudos podem ser decorrentes da localidade, condições edafoclimáticas, idade de implantação e espécies. No entanto, a principal diferença no aporte anual de serapilheira está provavelmente relacionada com a densidade das árvores dos plantios. Todos os trabalhos reportaram densidades de eucalipto variando de 1.142 a 
3.333 ind $\mathrm{ha}^{-1}$, sendo estas significativamente maiores que a área de ERN (427 ind ha ${ }^{-1}$ ) (Tabela 1). Segundo Souza e Davide (2001) e Pinto et al. (2008) a maior densidade de árvores aumenta a sobreposição das copas sobre o solo e, conseqüentemente um maior aporte de serapilheira.

\section{Frações da serapilheira nas duas áreas de estudo}

Foi constatada diferença estatística entre as frações da serapilheira quando comparada dentro da mesma área de estudo (ERN e FES). Somente a fração foliar apresentou diferença estatística do aporte médio entre as fontes de serapilheira (EUC, REG e FES). Os valores de aporte médio das frações seguiram uma mesma seqüência decrescente nas duas áreas de estudo: Folhas $>$ Ramos $=$ Outros $>$ Material reprodutivo (Tabela 3).

Tabela 3. Aporte médio* absoluto e relativo das frações da serapilheira nas duas áreas de estudo no município de Santa Teresa, Espírito Santo.

Table 3. Contribution average* absolute and relative of litter fractions in the two study areas in the municipality of Santa Teresa, Espírito Santo State.

\begin{tabular}{lcr}
\hline Frações & EUC & REG \\
\hline Folhas & $0,16(37 \%)$ b A & $0,13(28 \%)$ b A \\
Ramos & $0,06(13 \%)$ a B & $0,30(68 \%)$ a A \\
Material reprodutivo & $0,03(7 \%)$ a BC & $0,02(4 \%)$ a BC \\
Outros & $0,06(14 \%)$ a B & $0,06(14 \%)$ a B \\
\hline Total & $0,45(100 \%)$ a & $0,45(100 \%)$ a \\
\hline Legenda: EUC= serapilheira do eucalipto; REG= serapilheira da regeneração de espécies nativas no sub-bosque do plantio de eucalipto; FES= \\
serapilheira das espécies da Floresta Estacional Semidecidual. * Média dos 16 meses; Valores entre parênteses representam a proporção percentual \\
da fração relativo ao total aportado; Letras iguais minúsculas na linha e maiúsculas na coluna não apresentam diferença estatística pelo teste de \\
Tukey (p<0,05).
\end{tabular}

Tanto na ERN quanto na FES observou-se uma maior proporção das folhas em relação demais compartimentos (Tabela 3). Esse resultado corrobora com diversos autores que constataram que as folhas são os principais constituintes da serapilheira, o que evidencia a importância dessa fração na devolução de nutrientes ao solo (PINTO et al., 2008, 2009; SCHUMACHER et al. 2013).

\section{Correlação da deposição foliar entre as fontes e áreas de estudo}

A produção de serapilheira da área de ERN correlacionou-se positivamente com o aporte da fração foliar do eucalipto (EUC) $\left(\mathrm{p}<0,001 ; \mathrm{R}^{2}=0,89\right)$. Na mesma área não foi observada correlação com o aporte das outras fontes de material foliar da REG e FES. Esses resultados demonstraram que na área de ERN o padrão de deposição da serapilheira total foi influenciado, principalmente, pelo aporte de material foliar do eucalipto (EUC) e em menor proporção pelas folhas da REG.

Já na área de Floresta Estacional Semidecidual foram constatadas correlações positivas entre a deposição de folhas da REG e da própria floresta (FES) $\left(\mathrm{p}<0,001 ; \mathrm{R}^{2}=0,68\right)$. Neste sentido, é possível afirmar que as espécies nativas presentes nas áreas REG e FES seguem um mesmo padrão de deposição das folhas ao longo do ano. Esse padrão de deposição pode ser decorrente da similaridade florística entre as espécies da FES e da REG (41\%) (Tabela 1).

\section{Influência do clima na produção de serapilheira nas duas áreas de estudo}

$\mathrm{O}$ aporte de serapilheira total na área de ERN apresentou correlação positiva somente com as variáveis climáticas umidade relativa e precipitação (Tabela 4). Analisando somente a fração foliar do eucalipto, observou-se relação positiva desta com temperatura do ar, temperatura máxima e mínima, e precipitação. Portanto, as maiores deposições de serapilheira total na área ERN ocorreram na época do ano com maior umidade relativa e precipitação. Já para as folhas do eucalipto, as maiores deposições desta fração ocorreram nos meses de maiores temperaturas e precipitação (Tabela 4).

Poucos são os trabalhos que relacionam variáveis climáticas com a produção de serapilheira em plantios de eucalipto, sendo que a maioria dos resultados encontrados por diferentes autores são quase sempre inconclusivos. Schumacher et al., (2013) estudando o aporte de serapilheira em um plantio de eucalipto formado por um híbrido produzido por um cruzamento entre Eucalyptus urophylla e Eucalyptus globulus no Rio Grande do Sul, encontraram relação positiva entre a deposição de matéria orgânica e variáveis climáticas, porém todas baixas. Entretanto Barlow et al. (2007) encontraram relação positiva somente da precipitação com a deposição de folhas de Eucalyptus urophylla aos 4 e 5 anos de idade.

$\mathrm{Na}$ área de FES não foram verificadas correlações entre o aporte e as variáveis climáticas. No entanto, as folhas das áreas de FES e REG apresentaram uma relação semelhante com as variáveis climáticas. As folhas da área de REG e FES apresentaram correlação negativa com as temperaturas e precipitação, ou seja, nos meses com menores valores destas variáveis climáticas ocorreram menos aportes de material foliar (Tabela 4). Diversos autores apontam um maior aporte de serapilheira em áreas de Floresta Estacional Semidecidual nos meses de estiagem e baixas 
temperaturas, porém estes ainda não são conclusivos quanto à correlação entre produção de biomassa vegetal e variáveis climáticas (VITAL et al., 2004; PINTO et al., 2008, 2009; GODINHO, 2011).

Tabela 4. Correlação de Pearson da média do aporte de serapilheira $\left(\mathrm{Mg} \mathrm{ha}^{-1}\right)$ com as variáveis climáticas no município de Santa Teresa, Espírito Santo.

Table 4. Pearson correlation of the average leaf contribution $\left(\mathrm{Mg} \mathrm{ha}^{-1}\right)$ with the climatic variables in Santa Teresa, Espírito Santo State.

\begin{tabular}{|c|c|c|c|c|c|c|}
\hline Folhas & Tar & Tmáx & Tmin & $\mathbf{U r}$ & Evp & $\mathbf{P}$ \\
\hline EUC & $0,747 * *$ & $0,680 * *$ & $0,656^{*}$ & 0,427 & $-0,058$ & $0,597 *$ \\
\hline REG & $-0,722 * *$ & $-0,628 *$ & $-0,784 * *$ & 0,169 & $-0,166$ & $-0,547 *$ \\
\hline FES** & $-0,748 * *$ & $-0,679 * *$ & $-0,821 * *$ & $-0,389$ & 0,129 & $-0,543 *$ \\
\hline Áreas & Tar & Tmáx & Tmin & $\mathrm{Ur}$ & Evp & $\mathrm{P}$ \\
\hline ERN & 0,449 & 0,433 & 0,347 & $0,513^{*}$ & $-0,069$ & $0,528 *$ \\
\hline FES* & $-0,382$ & $-0,393$ & $-0,481$ & $-0,293$ & 0,094 & $-0,347$ \\
\hline
\end{tabular}

Legenda: ERN=plantio de eucalipto com regeneração de espécies nativas; FES*= Floresta Estacional Semidecidual; EUC= folhas do eucalipto; $\mathrm{REG}=$ folhas da regeneração de espécies nativas no sub-bosque do plantio de eucalipto; FES**= folhas das espécies da Floresta Estacional Semidecidual; Tar $=$ média da média da temperatura diária do ar $\left({ }^{\circ} \mathrm{C}\right)$; Tmáx $=$ média da temperatura máxima diária $\left({ }^{\circ} \mathrm{C}\right)$; Tmin $=$ média da temperatura mínima diária $\left({ }^{\circ} \mathrm{C}\right) ; \mathrm{Ur}=$ média da umidade relativa diária do ar; Evp= evapotranspiração média $(\mathrm{mm}) ; \mathrm{P}=$ precipitação média; *, ** Correlação de Pearson significativa a $5 \%$, e $1 \%$ respectivamente.

\section{Sazonalidade na produção de serapilheira nas duas áreas de estudo}

Foram constatadas diferenças significativas do aporte total de serapilheira ao longo do ano na área de ERN (Tabela 5). Também foi possível observar uma considerável deposição de serapilheira em dois períodos do ano. O primeiro entre os meses de dezembro a março e segundo entre os meses de junho a agosto. O primeiro é referente ao material foliar do eucalipto nos meses chuvosos (novembro a março) e o segundo é decorrente do aporte das folhas da regeneração de espécies nativas nos meses de estiagem (junho a setembro) (Tabela 2 e 5).

Também houve diferenças significativas da produção média anual da fração foliar entre as fontes de serapilheira (FES, EUC e REG) $(\mathrm{p}<0,05)$ (Tabela 5). A seqüência de aporte médio anual das folhas foi: FES> EUC=REG (Tabela 5). Nota-se que a maior densidade de árvores da FES (Tabela 1) é seguida pelo maior aporte de material foliar entre as diferentes fontes de serapilheira (FES, REG e EUC) (Tabela 5). Esses resultados corroboram com o padrão observado por Pinto et al. (2008), que verificaram uma correlação positiva $\left(\mathrm{P}<0,001 ; \mathrm{R}^{2}=0,66\right)$ entre o maior aporte de serapilheira e as parcelas que apresentavam maior densidade de indivíduos arbóreos. No entanto, não houve correlação entre densidade de árvores e o aporte de folhas entre a REG e EUC. Esse padrão demonstra que mesmo com densidades de árvores diferentes, a REG e o EUC apresentaram aporte de folhas semelhantes (Tabela 5).

Tabela 5. Produção média* mensal das fontes de fração foliar do eucalipto (EUC), regeneração de espécies nativas no sub-bosque do eucalipto (REG) e da Floresta Estacional Semidecidual (FES) no município de Santa Teresa, Espírito Santo.

Table 5. Average monthly* production of foliar fractions of sources to eucalyptus (EUC), native species regeneration in the understory of eucalyptus (REG) and the Semideciduous Forest (FES) in Santa Teresa, Espírito Santo State.

\begin{tabular}{llll}
\hline \multirow{2}{*}{ Meses } & \multicolumn{1}{c}{ EUC } & REG & FES \\
\cline { 2 - 4 } & & $0,22(0,07)$ b B & $0,94(0,103)$ a A \\
\hline Agosto & $0,04(0,007)$ c C & $0,11(0,03)$ c B & $0,51(0,085)$ a A \\
Setembro & $0,07(0,011)$ c C & $0,04(0,01)$ b C & $0,17(0,025)$ a B \\
Outubro & $0,04(0,006)$ b C & $0,05(0,01)$ b C & $0,24(0,047)$ a B \\
Novembro & $0,07(0,014)$ b C & $0,17(0,06)$ b B & $0,18(0,042)$ b B \\
Dezembro & $0,34(0,055)$ a AB & $0,05(0,01)$ c C & $0,03(0,001)$ c C \\
Janeiro & $0,47(0,065)$ a A & $0,04(0,01)$ c C & $0,10(0,015)$ c C \\
Fevereiro & $0,46(0,065)$ a A & $0,09(0,03)$ c BC & $0,18(0,025)$ b B \\
Março & $0,28(0,046)$ a AB & $0,05(0,01)$ b C & $0,14(0,012)$ a BC \\
Abril & $0,06(0,012)$ b C & $0,09(0,02)$ a BC & $0,15(0,034)$ a BC \\
Maio & $0,07(0,020)$ a C & $0,20(0,05)$ b B & $0,40(0,083)$ a AB \\
Junho & $0,04(0,008)$ c C & $0,41(0,11)$ b A & $0,60(0,084)$ a A \\
Julho & $0,04(0,010)$ c C & 1,51 & 3,64 \\
\hline Total & 1,97 & $0,13(0,03)$ b & $0,30(0,07)$ a \\
\hline Média & $0,16(0,05)$ b & 54,2 & 56,3 \\
\hline CV $\%)$ & 43,3 & & \\
\hline
\end{tabular}

Legenda: * Média dos coletores; valores entre parênteses representam o erro padrão da média. Letras iguais minúsculas na linha e maiúsculas na coluna não apresentam diferença estatística pelo teste de Tukey $(\mathrm{p}<0,05)$.

Padrão similar ao verificado nesse estudo foi encontrado por Balieiro et al. (2004) avaliando aporte de serapilheira em áreas de plantio de eucalipto em Seropédica, RJ. De modo geral, as deposições predominaram nos 
O potássio $(\mathrm{K})$ foi o macronutriente que apresentou, para todas as formações, o segundo maior valor de deposição. As folhas de FES apresentaram os maiores valores de deposição, quando comparadas à folhas do EUC e da REG (Tabela 6). Já o fósforo (P) foi o macronutriente que obteve menores aportes em todas as fontes de serapilheira avaliadas (Tabela 6). Esses resultados são corroborados com diversos autores que também observaram o potássio e fósforo como os macronutrientes de menor retorno ao solo em Florestas Estacionais Semideciduais (VITAL et al., 2004; PINTO et al., 2009; GODINHO, 2011).

Em geral os valores de aporte de macronutrientes das áreas de FES e REG foram menores comparados a outros estudos em Florestas Estacionais Semideciduais (VITAL et al., 2004; PINTO et al., 2009; GODINHO, 2011). As diferenças do retorno de macronutrientes constatada neste estudo podem ser decorrentes da localidade, condições edafoclimáticas, estádio sucessional e composição das espécies dos fragmentos avaliados. Porém, vale ressaltar que o presente estudo reportou o aporte de macronutrientes somente da fração foliar, enquanto os outros autores avaliaram o aporte total, com contribuição dos outros componentes do material formador da serapilheira (VITAL et al., 2004; PINTO et al., 2009; GODINHO, 2011).

O eucalipto quando comparado a outras espécies nativas produz uma serapilheira com menor conteúdo de nutrientes (GAMA-RODRIGUES; BARROS, 2002). No entanto, neste estudo o retorno de nutrientes pelo EUC não apresentou diferença significativa quando comparado à área REG (Tabela 6). O retorno de nutrientes aportados pelo EUC, em geral, se mostrou semelhante aos valores encontrados em outros trabalhos (GAMA-RODRIGUES; BARROS, 2002; CUNHA et al., 2005).

$\mathrm{O}$ aporte dos macronutrientes apresentou relação positiva com todas as suas respectivas fontes de serapilheira. A correlação de Pearson média para todas as respectivas fontes de serapilheira foi de 0,93 ( $P<0,001)$. Portanto, o retorno macronutrientes acompanhou o aporte das folhas ao longo do ano.

\section{Decomposição do material foliar}

As maiores perdas de massa foliar foram registradas nos primeiros 30 dias de permanência dos litter bags no campo, respectivamente $24 \%$ e $19 \%$ para FES e REG, enquanto EUC registrou a menor perda (6\%) no mesmo período.

Após 60 dias, não foram observadas perdas expressivas de material, e aos 120 dias, após o término das avaliações, o maior percentual de massa remanescente foi das folhas de eucalipto. Estudos realizados por Vital et al., (2004) e Pinto et al., (2009) em duas Florestas Estacionais Semideciduais localizadas em Botucatu (SP) e Viçosa (MG), respectivamente, verificaram padrões semelhantes aos observados na FES e REG, sendo quantificadas maiores perdas de massa no primeiro mês de avaliação. Esse padrão de decomposição é devido à degradação das substâncias e estruturas mais lábeis das folhas, fazendo que o material perca massa geralmente nos primeiros dias de exposição no ambiente.

O padrão de decomposição observado para as folhas de EUC é concordante com os padrões verificados em estudos semelhantes (HEPP et al., 2009; COSTA et al., 2005) que verificaram maiores perdas de massa nos últimos meses do experimento. De acordo com Costa et al., (2005) os povoamentos de eucalipto em regiões tropicais apresentam perda de massa normalmente inferiores a 50\% durante o ano, dependendo da espécie, idade, sistemas de manejo e condições edafoclimáticas.

Foram observadas diferenças significativas para a constante de decomposição (k) e tempo de meia vida $\left(\mathrm{T}^{1 / 2}\right)$ entre as frações foliares. Estes valores foram semelhantes entre a FES e REG, diferindo somente para a EUC. Já para o $\mathrm{T}^{1 / 2}$ das folhas de EUC foi aproximadamente o triplo das outras frações (FES e REG), necessitando de 347 dias para metade do material foliar se decompor. Sendo assim, verificou-se que a velocidade de decomposição da serapilheira da fração foliar obedeceu a seguinte ordem FES > REG > EUC (Figura 2a). Outros trabalham também constataram uma maior velocidade de decomposição da serapilheira de espécies nativas quando comparadas com plantios comerciais de eucalipto (DINIZ et al., 2011; HEPP et al., 2009; BALIEIRO et al., 2004).

A menor velocidade de decomposição do eucalipto deve-se, provavelmente, ao maior conteúdo de polifenóis e lignina presentes em sua composição em comparação às espécies nativas (Costa et al., 2005; Hepp et al., 2009). As maiores velocidades de decomposição e, conseqüentemente, menores $\mathrm{T}^{1 / 2}$ das folhas da REG e FES podem ser decorrente da dominância de espécies de leguminosas arbóreas (Fabaceae) (Tabela 1), responsáveis por adicionar material com maiores teores de nitrogênio, conferindo uma maior degradabilidade (DINIZ et al., 2011; FERNANDES et al., 2006; BALIEIRO et al., 2004). 


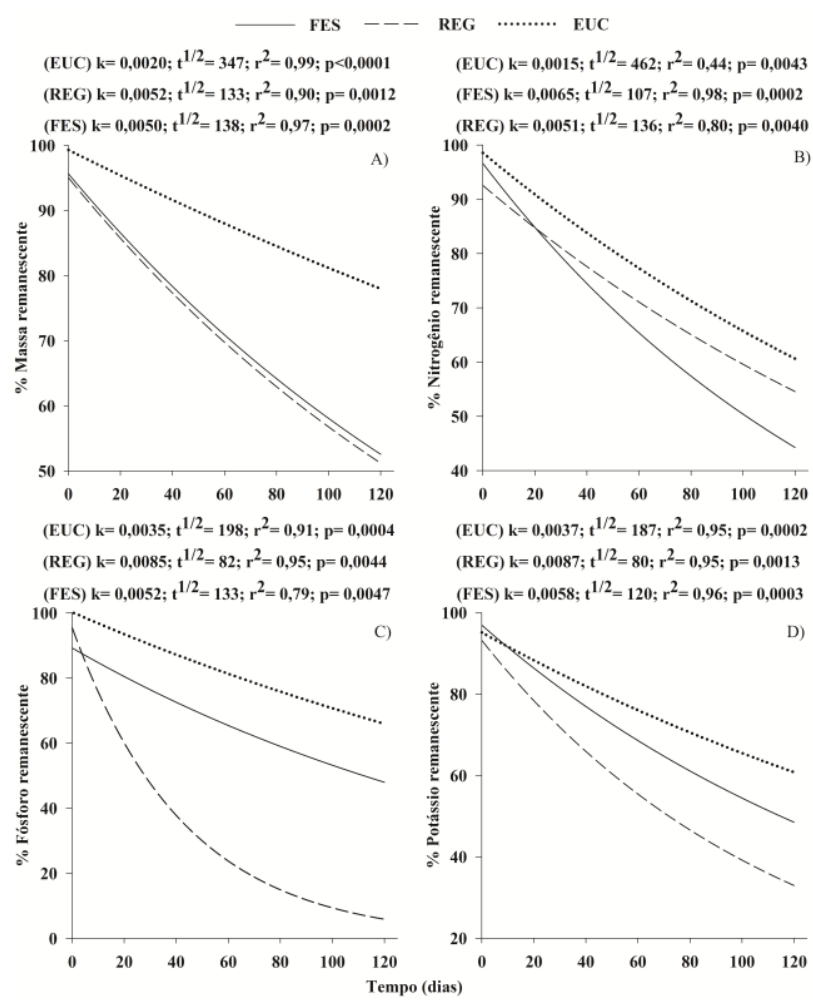

Figura 2. Curva de decomposição da biomassa e macronutrientes foliares no município de Santa Teresa, Espírito Santo. Legenda: $\mathrm{EUC}=$ Eucalipto; REG= Regeneração de espécies nativas; FES= Floresta Estacional Semidecidual; A) \% massa remanescente; B) \% de nitrogênio remanescente; C) \% de fósforo remanescente; D) \% de potássio remanescente.

Figure 2. Decomposition curve of biomass and leaf macronutrient in Santa Teresa, Espírito Santo State. Legend: $\mathrm{EUC}=$ eucalyptus; REG= regeneration of native species; FES= Semideciduous Forest; A) \% rmaining mass; B) $\%$ remaining nitrogen; C) \% remaining phosphorus; D) \% remaining potassium.

\section{Liberação de macronutrientes do material foliar}

A seqüência da velocidade de liberação do nitrogênio obedeceu a seguinte ordem: FES> REG> EUC (Figura 2b). A FES e REG apresentaram maiores velocidades de liberação do $\mathrm{N}$ devido a maior degradabilidade conferida por esse macronutriente nas folhas desses tratamentos. Já a menor velocidade de liberação de $\mathrm{N}$ das folhas de EUC deve-se, provavelmente, ao maior conteúdo de polifenóis e lignina presentes em sua composição (COSTA et al., 2005)

Para o fósforo verifica-se uma inversão da sequiência quanto à velocidade de liberação deste nutriente entre as frações foliares, sendo que a liberação obedeceu à seguinte ordem: REG > FES > EUC. Os menores valores do $\mathrm{T}^{1 / 2}$ para as folhas da REG (82 dias) seguido da FES (133) conferem a essas folhas maiores taxas de liberação P. Já para a área de EUC, o $T^{1 / 2}$ foi aproximadamente o dobro do observado nas outras frações foliares (REG e FES), necessitando de 198 dias para que metade do conteúdo de P seja liberado (Figura 2c). Logo após 20 dias de instalação dos litter bags, para as folhas da REG verificou-se um decaimento exponencial para a liberação de $\mathrm{P}$ significativamente mais rápido em comparação com os diferentes materiais (FES e EUC) restando cerca de $20 \%$ do material ao final do período de avaliação (Figura 2c).

Quanto à liberação do K, foi observado padrão similar ao verificado para o $P$, seguindo uma sequiência: REG> FES> EUC (Figura 2d). $\mathrm{O} \mathrm{T}^{1 / 2}$ das folhas de EUC foi aproximadamente o dobro das outras frações (REG e FES), necessitando de 187 dias para que metade do conteúdo de K foliar seja degradado. Embora as taxas de decomposição de $\mathrm{K}$ sejam diferentes, as curvas liberação deste macronutriente seguem o mesmo padrão de decaimento exponencial para todas as frações foliares (Figura 2d).

A velocidade de retorno dos macronutrientes seguiu a ordem: $\mathrm{N}>\mathrm{K}>\mathrm{P}$ para as folhas da FES e $\mathrm{K}>\mathrm{P}>\mathrm{N}$ para REG (Figura 2b, 2c e 2d). Pinto et al. (2009) também observaram uma seqüência da velocidade de liberação de macronutrientes de uma floresta em estádio inicial semelhante à REG $(K>P>N)$, enquanto na área de floresta avançada os autores observaram a mesma ordenação dos nutrientes da FES $(K>N>P)$. Estas diferenças nas sequiências da velocidade de liberação de macronutrientes se devem, provavelmente, ao diferente estádio sucessional apresentada por estas formações (FES e REG) (Tabela 1).

$\mathrm{O} \mathrm{T}^{1 / 2}$ para a liberação dos macronutrientes nas áreas de FES e REG foi mais elevado quando comparado a outros estudos realizados em florestas secundárias). Fernandes et al. (2006) reportaram tempo de meia vida para N, P e K da ordem de 10, 19 e 17 dias. Já Diniz et al. (2011) verificaram valores de tempo de meia vida para N, P e K de 39, 
32 e 8 dias respectivamente. Estas diferenças podem estar associadas à composição de espécies, idade da sucessão ecológica e fatores edafoclimáticos (PINTO et al., 2009).

Já as folhas de EUC apresentaram as menores constantes de decomposição e $\mathrm{T}^{1 / 2}$ para todos os macronutrientes (Figura 2b, 2c e 2d). Esse padrão indica que às folhas de EUC foram as que apresentaram as menores taxas de liberação dos macronutrientes no período de estudo. Segundo e Diniz et al. (2011) o maior $\mathrm{T}^{1 / 2}$ para os nutrientes foliares do EUC pode estar associado, ao maior teor de polifenóis, lignina e relação C:N na sua constituição, o que dificulta a ação dos agentes decompositores, aumentando o tempo de permanência dos nutrientes no material vegetal.

Quanto ao retorno dos macronutrientes para área de EUC foi observado a seguinte ordem: K > P> N (Tabela 6). Esse padrão também foi observado nos estudos de Gama-Rodrigues; Barros (2002) e Costa et al., (2005) que constataram uma maior lixiviação do K, liberação de N e acumulação de P na serapilheira de E. grandis.

Constata-se que as duas fontes de serapilheira (REG e EUC) na área do povoamento de eucalipto podem ser consideradas fatores positivos tanto para o solo e conseqüentemente quanto para a vegetação. As folhas da REG liberam os macronutrientes mais rapidamente, enquanto para as folhas de EUC o retorno destes ocorre de forma mais lenta e gradual para o ambiente, acarretando em uma menor lixiviação e perda destes macronutrientes. Adicionalmente um maior $\mathrm{T}^{1 / 2}$, oriundo das folhas de EUC, proporciona uma maior cobertura do solo, protegendo-o contra os processos erosivos principalmente nas épocas de maior precipitação.

\section{CONCLUSÃO}

- O método empregado foi adequado e suficiente para testar a hipótese do estudo. Os resultados obtidos neste estudo foram inéditos e de grande valia para a compreensão da ciclagem de nutrientes de plantios de eucalipto com regeneração nativa no sub-bosque.

- Neste estudo foi possível comparar o aporte anual total de serapilheira entre as duas áreas de estudo (ERN e FES) e dos macronutrientes das frações foliares do eucalipto, da regeneração nativa e da Floresta Estacional Semidecidual.

- $\quad$ O aporte de serapilheira e de macronutrientes foliares foram influenciados pelas variáveis climáticas da região.

- O método de litter bags verificou diferenças significativas entre as taxas de decomposição e liberação de macronutrientes foliares para todos os tratamentos.

- A dinâmica de produção e decomposição da serapilheira são fundamentais para a proteção e manutenção nutricional do solo nas duas áreas avaliadas.

\section{AGRADECIMENTOS}

Ao Instituto Federal de Educação, Ciência e Tecnologia do Espírito Santo de Santa Teresa pela autorização e apoio logístico do trabalho.

\section{REFERÊNCIAS}

ASSOCIAÇÃO BRASILEIRA DE FLORESTAS PLANTADAS (ABRAF). Anuário estatístico da ABRAF: ano base 2012. Brasília: ABRAF, 2013, 148 p.

ANDERSON, J. D.; INGRAM, J. S. I. Tropical soil biology and fertility: A handbook of methods. Wallingford, Oxfordshire: CAB International 2 ed. 1993, $171 \mathrm{p}$.

BAliEIRO, F. C.; FRANCO, A. A.; PEREIRA, M. G.; CAMPELlO, E. F. C.; DIAS, L. E; FARIA, S. M.; ALVES, B. J. R. Dinâmica da serrapilheira e transferência de nitrogênio ao solo, em plantios de Pseudosamanae guachapele e Eucalyptus grandis. Pesquisa Agropecuária Brasileira, Brasília, v. 39, n.6, p. 597-601, 2004.

BARRETO, P. A. B.; GAMA-RODRIGUES, E. F.; GAMA-RODRIGUES, A. C. Carbono das frações da matéria orgânica em solos sob plantações de eucalipto de diferentes idades. Scientia Forestalis (IPEF), v. 42, p. 571-580, 2014.

BARLOW, J.; GARDNER, T. A.; FERREIRA, L. V.; PERES C. A. Litter fall and decomposition in primary, secondary and plantation forests in the Brazilian Amazon. Forest Ecology and Management, v. 247, n. 2. p. 91-97, 2007.

CONAMA. Resolução 029 de 7 de dezembro de 1994. Ministério do Meio Ambiente. Disponível em: <http://www.idaf.es.gov.br>. Acesso em: 23 jun 2015.

COSTA, G. S.; GAMA-RODRIGUES, A. C.; CUNHA, G. M. Decomposição e liberação de nutrientes da serapilheira foliar em povoamentos de Eucalyptus grandis no norte fluminense. Revista Árvore, Viçosa, v. 29, n. 4, p. 563-370, 2005.

CUNHA, G. M.; GAMA-RODRIGUES, A. C.; COSTA, G. S. Ciclagem de nutrientes em Eucalyptus grandis W. Hill ex Maiden no norte fluminense. Revista Árvore, Viçosa, v. 29, n. 3, p. 353-363, 2005.

DINIZ, A. R.; PEREIRA, M. G.; LOSS, A. Aporte de material decídua e nutrientes para o solo em plantio de eucalipto e floresta secundária. Pesquisa florestal brasileira, Colombo, v. 31, n. 65, p. 19-26, 2011. 
FERNANDES, M. M.; PEREIRA, M. G.; MAGAlhÃES, L. M. S.; CRUZ, A. R.; GiÁCOMO. R. G. Aporte e decomposição de serapilheira em áreas de floresta secundária, plantio de sabiá (Mimosa caesalpiniaefolia benth.) e andiroba (Carapa guianensis aubl.) na FLONA Mário Xavier, RJ. Ciência Florestal, Santa Maria, v. 16, n. 2, p. 163$175,2006$.

FRANCO, A. A.; CAMPEllo, E. F. C.; MONTEIRO, E. M. S.; FARIA, S. M. 1992. Revegetação de solos degradados. Seropédica: Comunicado Técnico 09, Embrapa Agrobiologia, 1992, 201 p.

GAMA-RODRIGUES, A. C.; BARROS, N. F. Ciclagem de nutrientes em floresta natural e em plantios de eucalipto e de dandá no sudeste da Bahia, Brasil. Revista Árvore, Viçosa, v. 26, n. 2, p. 193-207, 2002.

GODINHO, T. O. Quantificação de biomassa e de nutrientes na serapilheira em trecho de Floresta Estacional Semidecidual Submontana, Cachoeiro de Itapemirim, ES. 114 f. Dissertação (Mestrado em Ciências Florestais) Universidade Federal do Espírito Santo, Alegre, 2011.

HEPP, L. U.; DELANORA, R.; TREVISAN A. Compostos secundários durante a decomposição foliar de espécies arbóreas em um riacho do sul do Brasil. Acta Botanica Brasilica, Belo Horizonte, v. 23, n. 2, p. 407-413, 2009.

INSTITUTO BRASILEIRO DE GEOGRAFIA E ESTATÍSTICA (IBGE). 2012. Manual técnico da vegetação brasileira. Instituto Brasileiro de Geografia e Estatística. Rio de Janeiro: IBGE, 2 ed. 2012, 275 p.

LOPES, M. I. M.; DOMINGOS, M.; VUONO, Y. S. Ciclagem de nutrientes minerais. In: SYLVESTRE, L. S.; ROSA, M. M. T. Manual metodológico para estudos botânicos na Mata Atlântica. Seropédica: Ed EDUR, 2002,42 p.

PINTO, S. I. C.; MARTINS, S. V.; BARROS, N. F.; DIAS, H. C. T. Produção de serapilheira em dois estádios sucessionais de Floresta Estacional Semidecidual na Reserva Mata do Paraíso em Viçosa, MG. Revista Árvore, Viçosa, v. 32, n. 3, p. 545-556, 2008.

PINTO, S. I. C.; MARTINS, S. V.; BARROS, N. F.; DIAS, H. C. T. Ciclagem de nutrientes em dois trechos de floresta estacional na Reserva Florestal Mata do Paraíso, em Viçosa, MG, Brasil. Revista Árvore, Viçosa, v. 33, n. 4, p. 653$663,2009$.

REZENDE, C. P.; CANTARUTTI, R. B.; BRAGA, J. M.; GOMIDE, J. A.; PEREIRA, J. M.; FERREIRA, E.; TARRÉ, R.; MACEDO, R.; ALVES, B. J. R.; URQUIAGA, S.; CADISCH, G.; GILLER, K. E.; BODDEY, R. M. Litter deposition and disappearance in Brachiaria pastures in the Atlantic Forest region of the south of Bahia, Brazil. Nutrient Cycling Agroecosystems, Amsterdam, v. 54, n. 2, p. 99-112, 1999.

SCHUMACHER, M. V.; CORRÊA, R. S.; VIERA, M.; ARAÚJO, E. F. Produção e decomposição de serapilheira em um povoamento de Eucalyptus urophylla x Eucalyptus globulus maidenii. Cerne, Lavras, v. 19, n. 3, p. 501-508, 2013.

SOUZA, J. A.; DAVIDE, A. C. Deposição de serapilheira e nutrientes em uma mata não minerada e em plantações de bracatinga (Mimosa scrabella) e de eucalipto (Eucalyptus saligna) em áreas de mineração de bauxita. Cerne, Lavras, v. 7, n. 1, p. 101-103, 2001.

SOUZA, P. B.; MARTINS, S. V.; COSTALONGA, S. R.; COSTA, G. O. Florística e estrutura da vegetação arbustivoarbórea no sub-bosque de um povoamento de Eucalyptus grandis W. Hill ex Maiden, em Viçosa, MG, Brasil. Revista Árvore, Viçosa, v. 31, n. 3, p. 533-543, 2007.

TEDESCO, M. J.; GIANELLO, C.; BISSANI, C. A.; BOHNEN, H.; VOLKWEISS, S. J. 1995. Análise de solo, plantas e outros materiais. Porto Alegre: UFRGS, 2ed. 1995. 174 p.

THOMAS, R. J.; ASAKAWA, N. M. Decomposition of leaf litter from tropical forage grasses and legumes. Soil Biology and Biochemistry, v. 25, n. 10, p. 1351-1361, 1993.

VITAL, A. R. T.; GUERRINI, I. A.; FRANKEN, W. K.; FONSECA, R. C. B. Produção de serapilheira e ciclagem de nutrientes de uma floresta estacional semidecidual em zona ripária. Revista Árvore, Viçosa, v. 28, n. 6, p. 793-800, 2004. 